\title{
Bellicum Pharmaceuticals
}

National Cancer Institute

\section{Source}

National Cancer Institute. Bellicum Pharmaceuticals. NCI Thesaurus. Code C134823.

A biopharmaceutical company focused on developing cellular immunotherapies for hematological cancers, solid tumors, and orphan inherited blood diseases. 